\title{
Comparison of price elasticity of demand for eggs in Lithuania and Ukraine
}

\section{Laura Petrauskaitè-Senkevič}

\section{Lithuanian Institute of Agrarian Economics, Vilnius, Lithuania}

Keywords:

\section{Egg}

Demand

Price

Elasticity

Lithuania

Ukraine

\section{Article history:}

Received 21.01.2020

Received in revised form 27.05.2020

Accepted 30.06.2020

\section{Corresponding author:}

Laura

Petrauskaitè-Senkevič E-mail:

laura.petrauskaite@laei.lt

DOI: $10.24263 / 2310-$ 1008-2020-8-1-13

\section{Abstract}

Introduction. Elasticity is a measure that shows how strongly buyers and sellers respond to changes in market conditions. Price elasticity of demand for eggs in Lithuania and Ukraine is presented in this work.

Materials and methods. While measuring price elasticity of demand for eggs in Lithuania and Ukraine, statistical data from 2003-2018 gathered by Statistics Lithuania and State Statistics Service of Ukraine was used. Data analysis, comparison and generalization were among the methods used. The annual coefficient of price elasticity of demand for eggs was calculated using the midpoint formula. An average, multi-annual coefficient of price elasticity of demand for eggs was calculated using the median. To demonstrate the results visually, the graphs below were used.

Results and discussion. It was established that in 20032018, fluctuation in the retail prices of eggs occurred both in Lithuania and Ukraine. In Ukraine it was clearer. During the period under investigation, the tendency to an increase of retail prices prevailed. To compare 2018 to 2003, the retail price of eggs in Lithuania increased by 1,9 times, and in Ukraine by 4,5 times. Despite a rapid increase in price, in 2003-2018 eggs were cheaper in the Ukrainian retail market.

The analysis of demand for eggs in Lithuania and Ukraine showed that customers reacted to the fluctuation in prices for just a short period of time. When the price of eggs increased, the consumption of eggs decreased; later, however, despite a further increase in price, usage was to return to the previous level.

Based on the data showing prices and usage, the coefficients of price elasticity of demand for eggs in Lithuania $(0,28)$ and Ukraine $(0,35)$ were calculated.

Conclusions. The study shows the hypothesis, that in Lithuania and Ukraine the demand for eggs is price inelastic, to be true. 


\section{Introduction}

Market conditions are unstable. As they change, so does the demand for, and supply of, goods. The elasticity index is used to measure these changes. Elasticity is a measure that shows how strongly buyers and sellers respond to changes in market conditions.

When the demand for a product changes due to its price, it is called price elasticity of demand. This index indicates how the degree of demand, measured as a percentage, changes in response to a one percent change in price. Depending on the ratio of change in demand $(\%)$ to change in price (\%), this elasticity can be of several kinds. Absolute elasticity is when a tiny price change (\%) precipitates a big change in the amount of demand $(\%)$. In this case, the coefficient of elasticity is infinite. Absolute inelasticity is when the change in price does not affect the change in the amount of demand. In this case the coefficient of elasticity equals zero. Cross-price elasticity shows the strength of connection between the change in price (\%) of one good and the change in quantity (\%) of another good. Relational elasticity is when the prices change by a smaller amount (\%) than the amount of change in demand (\%). The coefficient of elasticity is then higher than one. Relational inelasticity is when the change in price (\%) is higher than the amount of change in demand (\%). In this case the coefficient of elasticity is smaller than one.

Price elasticity of demand is determined by a multitude of factors: availability of substitutes, household income, consumer preferences, the expected duration of the price change, and the product's share of a household's income [11]. Multiple factors work collectively to shape goods demand including traditional economic determinants as well as non-traditional determinants such as health, nutrition, and food safety information; changing product characteristics and new product developments; and shifts in consumer demographics and lifestyles [16].

A variety of economic studies in foreign countries has shown that the demand for victuals is prices inelastic. R. Pomboza and M. Mbaga [12] analyse enquiries into elasticity of demand for victuals conducted in Canada in 20 years. The authors they mention have performed multiple enquiries into elasticity of demand for victuals; these have unanimously shown demand for victuals to be inelastic.

In 2010, scientists at Yale University [1] carried out a study in which they reviewed 160 existing studies about price elasticity of demand for main food products. Having summed up the examined data, they presented the average level of price elasticity of demand for various food products in the US between 1938 and 2007. This study also affirmed that demand for food products is inelastic. In their list, the smallest price elasticity of demand (the coefficient of 0,27 ) was assigned to eggs.

Small price elasticity of demand for victuals is also mentioned in the works of C.A. Gallet [5, 6], and also R. Green et al. [7], where the authors drew their estimates of own-price elasticities for food from 136 studies in 162 countries.

The abundance of scientific studies in foreign countries about this topic affirms that observation of demand is important. Even when indicators are established, it is useful to renew the calculations, as the market does not stand still. Over time, new dimensions of demand may arise and the relative importance of previously examined determinants may adjust in response to new information and economic conditions. An on-going demand estimation is important for informed decision-making by industry stakeholders and policy makers [9]. Food demand elasticities are important criteria often used to analyse long-term projections in order to assess the effects of political reforms or to shed light on a variety of issues. 
Very few studies have been conducted to investigate the price elasticity of demand for food products in Lithuania and Ukraine. In addition, these studies have been conducted for a long time ago and are of little relevance to this day. For example, the price elasticity of demand for food products in Lithuania has been examined in 2013 (eggs in the period 20032012) [13]. The price elasticity of demand for food products in Ukraine was examined in several works in 2005 (chocolate in the period 2001-2004) [3] and 2013 (fish in 2005) [12].

Due to such scarce research and old information this research was aimed at determining the elasticity of demand for eggs in relation to the changes in price of eggs in Lithuania and Ukraine. To achieve this aim, (1) a review of the literature on estimates for elasticity of food demand was conducted, (2) a review of prices and consumption of eggs was performed and (3) price elasticity of the demand for eggs in Lithuania and Ukraine was calculated.

Eggs were chosen for the study because they are relatively cheap in comparison with other livestock products. They are easily available on the market and easy to process, so eggs are always considered an important commodity to many consumers.

\section{Materials and methods}

To discover what results other scientists obtained while researching the elasticity of victuals, the works of other authors were examined, applying the methods of theoretical analysis, data interpretation, synthesis, logical comparison, systematization and generalization. While calculating price elasticity of demand in Lithuania and Ukraine, the statistical data from 2003-2018 collected by Statistics Lithuania and State Statistics Service of Ukraine was used. The monthly data is aggregated into yearly frequency using average values. The methods of statistical data analysis, comparison and generalization were applied. The coefficient of price elasticity of demand can be calculated by several methods:

* The Percentage Method. This method measures price elasticities of demand on the basis of a demand schedule and computes the percentage change in the quantity of a commodity demanded resulting from a given percentage change in its price [18].

* Point-price elasticity of demand. The point elasticity of demand method is used to identify change in demand within the same demand curve. However, this formula is inappropriate when price and quantity changes are large.

* Arc elasticity or Midpoint formula. The advantage of the midpoint method is that one get the same elasticity between two price points, there is no matter a price increase or decrease. It is because the formula uses the same base for both cases [23]. However, the greater the arch of the actual demand curve is over that range, the worse this estimation of its elasticity will be, because this formula implicitly presumes the part of the demand curve between those points is linear.

* The Total Outlay Method. This method compares the total expenses of a consumer both before and after the change in price. In this way, it is find out whether price elasticity of demand for a good is elastic, unity or less elastic. [18].

The coefficient of price elasticity of demand for eggs was calculated referring to various scientists $[2,3,4,8,10,13,14]$ who offer the midpoint formula:

$$
\left|E_{d}\right|=\frac{\frac{Q_{d}}{\left(Q_{d 1}+Q_{d 2}\right) / 2}}{\frac{\Delta P}{\left(P_{1}+P_{2}\right) / 2}}
$$


where Ed is the coefficient of price elasticity of demand for eggs, $\mathrm{Q}_{\mathrm{d}}$ is the amount of eggs consumed, $\Delta \mathrm{Q}_{\mathrm{d}}$ is the change in amount, $\mathrm{P}$ is the eggs price, $\Delta \mathrm{P}$ is the change in price.

As the annual elasticity indices for each of the countries under study had some unusual deviations, the average multi-annual coefficient of price elasticity of demand for eggs was calculated using a median. When the curve of demand has a negative slope, the value of elasticity is negative. Economists agree that the further the coefficient of elasticity is from zero, the more elastic the demand is. Thus, in this article, the absolute size of elasticity was used. The significance for this study was chosen at $5 \%$ level.

To demonstrate the results clearly, the graphs below were used. Our conclusions were offered using the method of generalization.

\section{Results and discussion}

\section{Tendencies of price and consumption}

The review of literature has shown that scientific research about price elasticity of demand for victuals is abundant. Price elasticity of the demand for individual victuals, however, was little researched in Lithuania and Ukraine. Theoretically, it is plausible that demand for eggs in both countries is price inelastic, yet indicators of elasticity had not been calculated in recent years. This work used the indicators of retail price and consumption of eggs in Lithuania and Ukraine. To avoid the derogations due to big seasonal fluctuations (which are especially relevant to egg price), and to avoid distortions (which could be produced during a short period of investigation when the users adapt to new conditions), annual indicators were taken and the period of 16 years was chosen.

Statistical data [18] indicates that the retail price of eggs in Lithuania in 2003-2018 increased by 1,9 times on average (Figure 1). The highest price recorded during this period was greater than the lowest by more than 3 times.

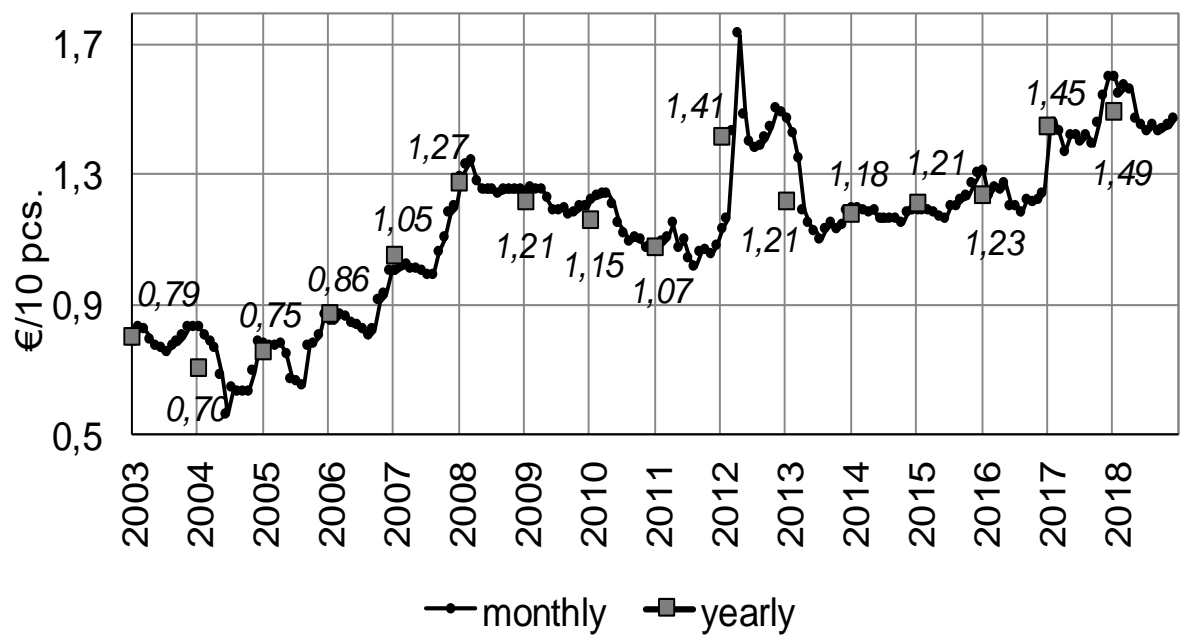

Figure 1. Retail price of eggs in Lithuania in 2003-2018 
In Lithuania in 2003-2018, the retail price of eggs grew in three stages. The first began in 2004 and continued until 2008. Over three years and nine months, the price increased by 2,4 times. Then, the retail price of eggs decreased for several years. In August 2011, it reached its lowest level at almost 24 per cent below March 2008. Straight after that, however, the second, rapid, stage of increasing prices began. Over eight months, the retail price of eggs in Lithuania increased by more than 1,7 times. These changes in the retail price of eggs were not unexpected. The reasons for this growth were twofold. First, the price increased (just as every year) due to seasonality. The other reason was the change made by the European Union to its requirements for the keeping of laying hens, starting in 2012. The latter condition had the biggest influence on the unusual increase in price. Finally, in 2012, after Easter, the retail price of eggs in Lithuania decreased; yet it was higher than in the corresponding period of previous years. On average in 2012, the retail price of eggs was higher by almost a third than in 2011 and exceeded by more than a tenth its previous high point in 2008. In 2013 the retail price of eggs decreased until July. Later, there came a gradual growth in price that continued until the beginning of 2018. Then, over four years and seven months, the retail price of eggs increased by 45 per cent.

During the period under investigation, 2003-2018, the annual consumption of eggs per capita in Lithuania increased by 33 per cent (Figure 2) [21].

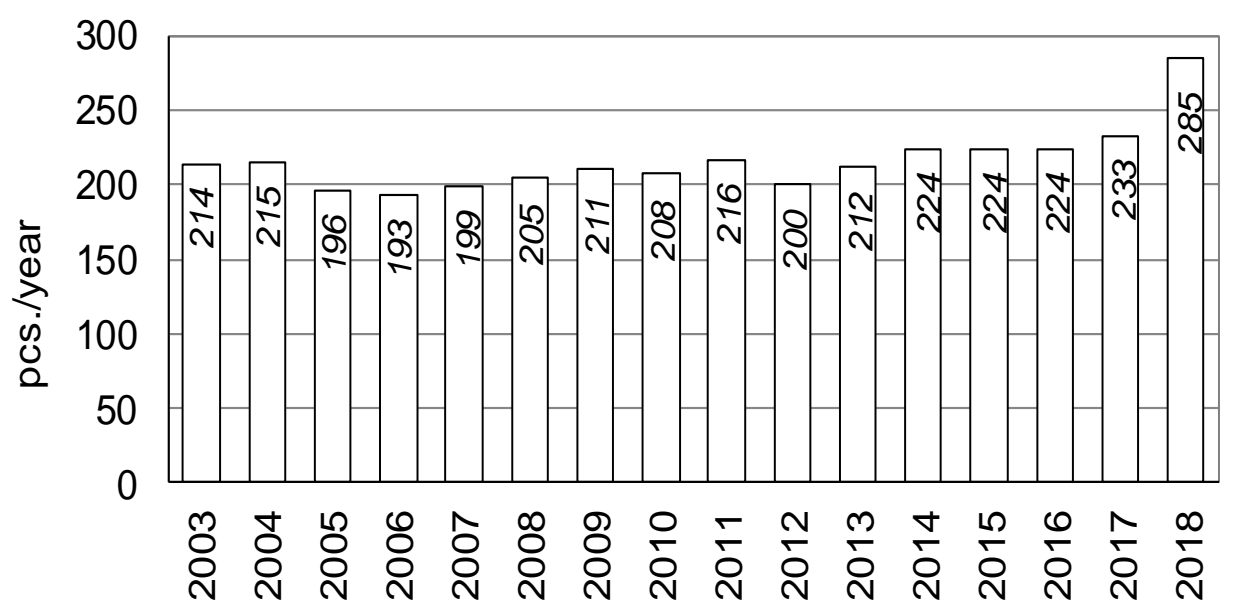

Figure 2. Consumption of eggs per capita in Lithuania in 2003-2018

A more detailed analysis reveals that each change in the price of eggs exerted only a brief influence. When the price increased or decreased, the demand for eggs was deflected to the opposite side. Yet when consumers got used to the changes in price, the demand for eggs would subsequently begin to grow.

In 2005 and 2006 the price of eggs in comparison to the previous year increased 7 per cent and 15 per cent. At that time, demand decreased by 9 and 2 per cent. Later, the price grew further; when users did not find suitable substitutes for eggs - despite their growing price - their demand also grew until it reached a level similar to that prevailing before the growth in price. A similar sequence occurred in 2012. When price grew by 32 per cent, the consumption of eggs in Lithuania decreased by 7 per cent. 
Retail price of eggs in Ukraine in 2003-2018 was on average 16 per cent lower than in Lithuania (Figure 3) [17, 19, 20].

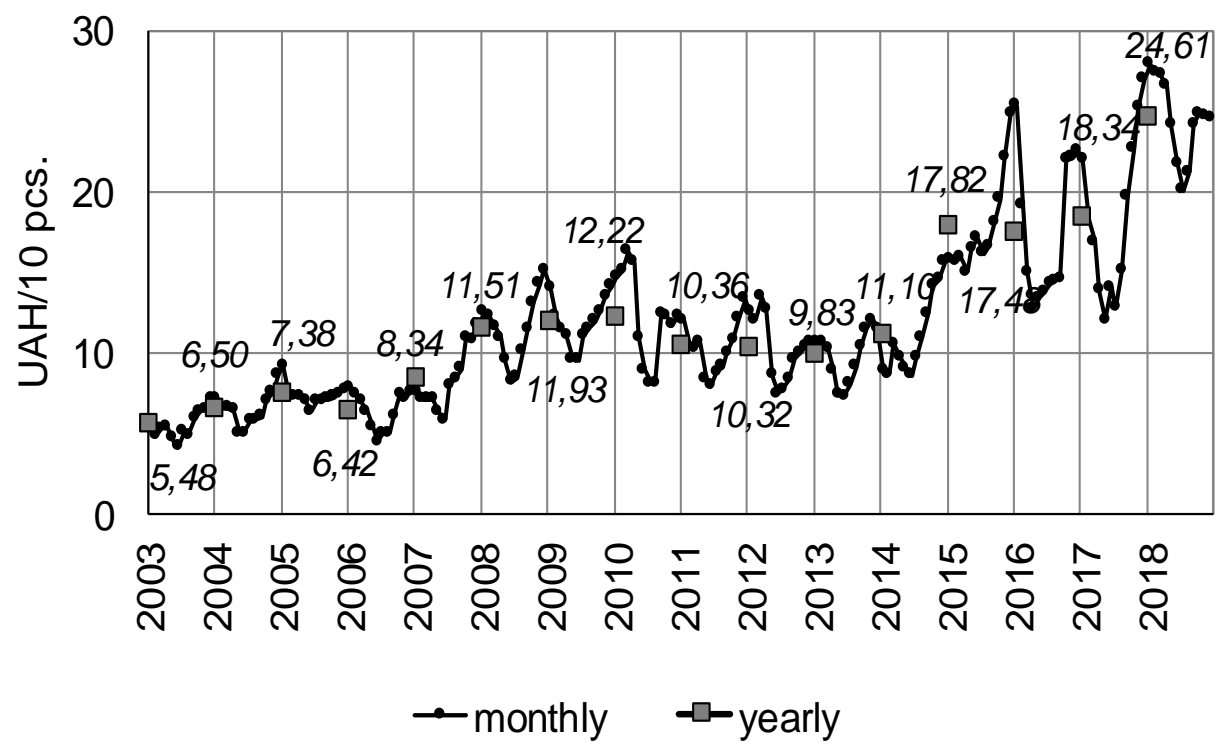

Figure 3. Retail price of eggs in Ukraine in 2003-2018

In Ukraine the retail price of eggs was marked by clearer seasonal fluctuations than in Lithuania. During the period under investigation, the difference of retail price of eggs in the summer-winter season was 17 per cent in Lithuania, then in Ukraine this indicator was as much as 63 per cent.

In 2003-2018 the retail price of eggs in Ukraine, just as in Lithuania, grew, but by significantly more, 4,5 times. The difference between the lowest and the highest price in this period was on 6,7 times.

In Ukraine, in 2003-2018, the retail price of eggs grew in two stages. The first continued from the middle of 2003 until the beginning of 2010. Then, over six years and ten months the price increased by 3,9 times. Later, the retail price of eggs decreased for several years. In June of 2013, it reached its lowest level, 2,2 times below March 2010. Then, the second stage of price growth began, which lasted until the beginning of 2018. Retail price of eggs in Ukraine grew by more than 3,8 times over four years and eight months. In comparison to Lithuania, all the fluctuations in egg price in Ukraine were markedly higher. In Ukraine they were influenced by seasonal fluctuations, global egg price tendencies and inflation in the country.

During the period under investigation in 2003-2018, the annual consumption of eggs per capita increased by 28 per cent (Figure 2) [15]. But the biggest leap in consumption in comparison to 2003 happened in 2011 and 2014, when it was 45 per cent. After 2014 somewhat fewer eggs were used in the country. 


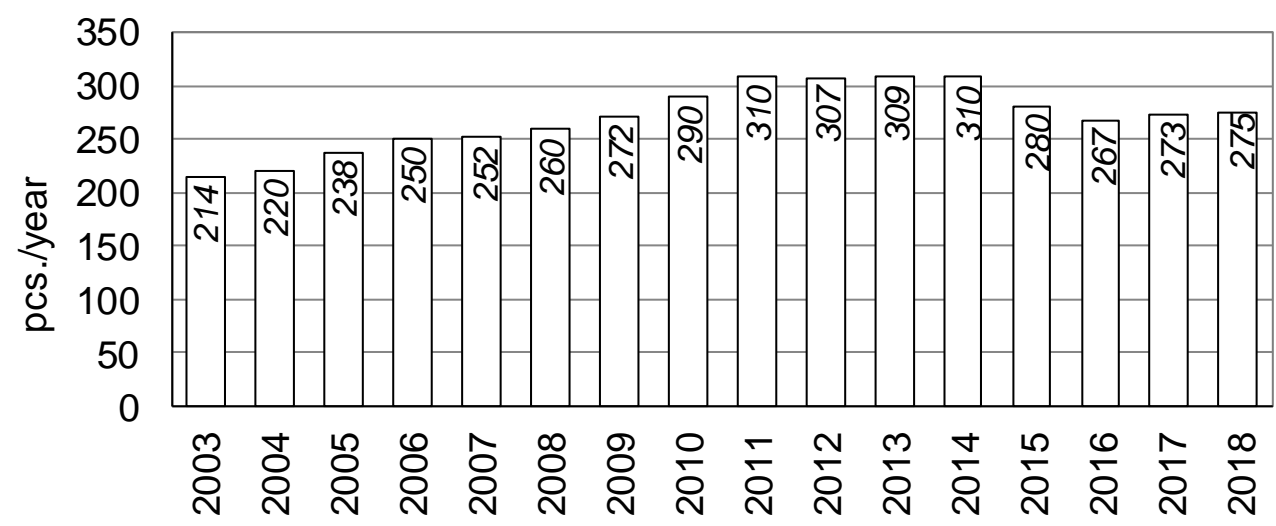

Figure 4. Consumption of eggs per capita in Ukraine in 2003-2018

In Ukraine, just as in Lithuania, the consumption of eggs depends little on trends in price. In this country in 2003-2010 when the retail price of eggs increased, the consumption of these products simply increased. Somewhat fewer eggs were used in Ukraine just after 2014, when the price of the eggs was to increase significantly over a relatively short time. In Lithuania, a similar situation took place in 2012. Yet experience was to show that the consumption of eggs would quickly return to previous level. Therefore, it is plausible that in Ukraine, too, the consumption of these products will go back to the level of 2011-2014.

\section{Price elasticity of demand}

These changes in the consumption of eggs and in their retail prices allows one to suppose that in both Lithuania and Ukraine, just as in those countries where the above-mentioned scientists conducted their research, there was a price inelasticity of demand for eggs. To confirm such a hypothesis, calculations based on statistical data were conducted, based on the formula shown above. They showed that, in the long term, and in both countries, the demand for eggs is price inelastic and statistically significant $(p=0,00<0,05)$.

The results obtained show that, in spite of the fact that the indicator of elasticity in the course of separate years fluctuated from one side to the other, the multiannual tendency in Lithuania was, the demand for eggs to be relatively price inelastic $(0,28)$. Its inelasticity level was similar to that in the case of the USA $(0,27)$, where scientists examined the experience of almost 70 years [1]. In Ukraine price elasticity of the demand for eggs in 2003-2018 was just a little higher $(0,35)$ than in Lithuania. Yet in this country the demand for eggs was price inelastic too.

The results allow us to suppose that, despite changes in the price of eggs, their consumption, taking the long view, would not be significantly altered unless other conditions were also to change. The situation could be changed by innovations in science and the food industry, which would allow other nutritional products for humans to be substituted for eggs. There are scarcely any natural substitutes for eggs and, at this point, the various mixtures consisting of several elements of vegetable or animal origin cannot be substituted for eggs. 


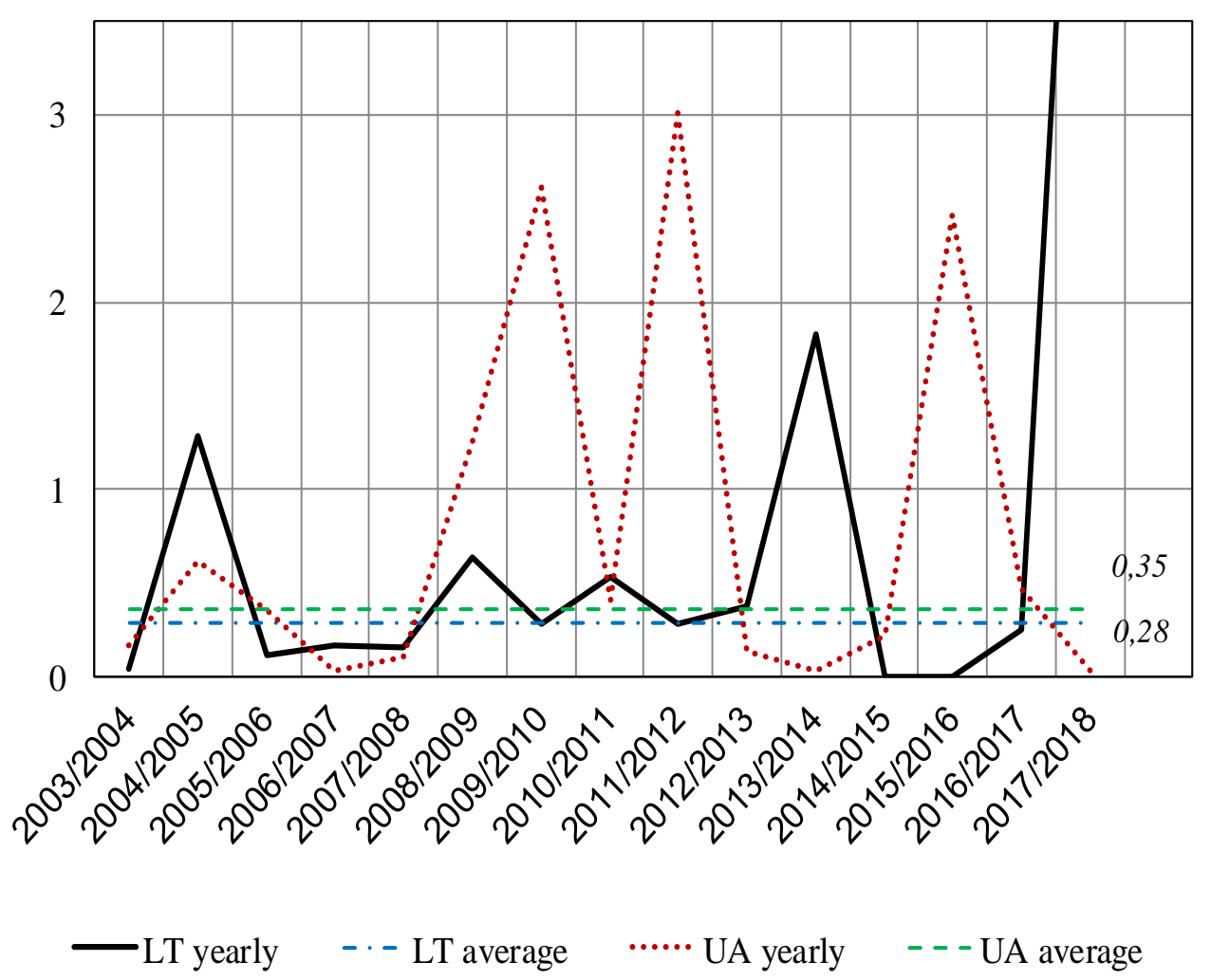

Figure 5. Price elasticity of demand for eggs in Lithuania and Ukraine in 2003-2018

There are no studys that provides consistent observation of price elasticity of demand for food in the Lithuania and Ukraine. This study set out to address this gap by estimating price elasticity of demand for egg. The results obtained here are recommended for the use of manufacturers. If producer want successfully compete on a market, he have to have relevant information. Talking about marketing, it is impossible to conduct an effective policy, to plan production and other processes without exact knowledge about the demand for the product ant its determinants. The price elasticity of demand is the most important thing that a producer should know. Knowledge of elasticities allow to gain a sense of how markets and the consumers react to price changes. It allow producers to make the most effective production, pricing and advertising decisions targeting either sales or profit magnification.

The results might also be useful to the government sector in making various decisions, carrying out calculations and forecasting. To increase the efficiency of the tax system, tax authorities should know price elasticity for each product and service in the market, also regularly estimate elasticity after the change of consumer priority or after the new products entreance in the market, because they can affect elasticity of demand for existing products.

Knowledge of price elasticity of demand for food allow the government sector to estimate the market conditions, to make informed decisions in the context of food assistance programmes, to ensure that the vulnerable segments of the population have access to food and which food stuff to target in food aid programmes. 
Alas, price elasticity of demand for eggs is not favourable to consumers. They are, however, the ones whose actions produce the phenomenon; therefore, by being better informed and by showing more initiative, consumers could change the situation to their own advantage by always searching out new substitutes for eggs.

The regular need for knowledge of the price elasticity of demand suggests that periodic calculations of this indicator should be carried out in the future, not only for eggs but also for all other important food products. This information could be used by both the private and public sectors to make important decisions.

\section{Conclusion}

While analysing the retail price of eggs in Lithuania, it was established that over the period 2003-2018 it increased by 1,9 times. This growth in price occurred in several stages. From 2004 to 2008, the retail price of eggs increased by 2,4 times. After a small decrease in 2011-2012, a rapid and significant second leap in price occurred; over eight months the price increased more than 70 per cent. After a period of decreasing prices in 2013, the third growth period in the retail price of eggs began. It went on until 2018 and during that period the price increased by 45 per cent.

In Ukraine the retail price of eggs during the period under investigation was lower than in Lithuania; nevertheless, the fluctuations were more pronounced. In 2003-2018, the retail price of eggs increased by 4,5 times. This growth of price happened in several stages. In 2003-2010, the retail price of eggs increased by 3,9 times. Until the middle of 2013, a decrease in price ensued, and later the second stage of price growth began, which continued until 2018. During that period, retail price grew by 3,8 times.

The analysis of egg demand in Lithuania and Ukraine shows that consumers reacted to changes in price for just a short time. When the price grew, consumption of eggs was to decrease somewhat, but, despite the fact that the price was then to grow further, consumption would return to the previous level.

Using data for price and consumption over 16 years, the coefficients of price elasticity of demand for eggs in Lithuania and Ukraine were calculated. These calculations showed that demand for eggs in both countries was price inelastic. The average coefficient of elasticity during the period under investigation in Lithuania was 0,28 and in Ukraine it was 0,35 .

The results obtained here are recommended for use by the production and government sectors in planning their activities and in forecasting future results. Consumers who want to change the situation into one more favourable to themselves, should find substitutes for eggs.

\section{References}

33. Andreyeva T., Long M. W., Brownell K. D. (2010), The impact of food prices on consumption: a systematic review of research on the price elasticity of demand for food, American Journal of Public Health, 100(2), pp. 216-222.

34. Bade R., Parkin M. (2015). Foundations of Microeconomics, $7^{\text {th }}$ edition, Pearson, New Jersey.

35. Bezpalyy Y. (2005), Estimation of demand elasticities for chocolate tablets in Ukraine, National University "Kyiv-Mohyla Academy”, Kyiv. 
36. Chiang E., Stone G. W. (2014), Core Microeconomics, $3^{\text {rd }}$ edition, Worth Publishers, New York.

37. Colander D. C. (2013), Microeconomics, $9^{\text {th }}$ edition, McGraw-Hill, New York.

38. Gallet C. A. (2009), The demand for fish: a meta-analysis of the own-price elasticity, Aquaculture Economics \& Management, 13(3), pp. 235- 45.

39. Gallet C. A. (2010), Meat meets meta: a quantitative review of the price elasticity of meat, American Journal of Agricultural Economics, 92(1), pp. 258-72.

40. Green R., Cornelsen L., Dangour A. D., Turner R., Shankar B., Mazzocchi M., Smith R. D. (2013), The effect of rising food prices on food consumption: systematic review with metaregression, British Medical Journal, 346:f3703.

41. Krugman P., Wells R. (2014), Microeconomics, $4^{\text {th }}$ edition, Worth Publishers, New York.

42. Lusk J. L., Tonsor G. T. (2016), How meat demand elasticities vary with price, income, and product category, Applied Economic Perspectives and Policy, 38(4), pp. 673-711.

43. Mankiw N. G. (2018), Principles of Microeconomics, $8^{\text {th }}$ edition, Cengage Learning, Mason.

44. Muhammad A., Seale J.L., Meade B., Regmi A. (2011), International evidence on food consumption patterns: an update using 2005 international comparison program data, United StatesDepartment ofAgriculture, Washington.

45. Petrauskaite-Senkevic L. (2013), Price elasticity of demand for eggs in Lithuania, Management theory and studies for rural business and infrastructure development, 35(4), pp. 604-614.

46. Pindyck R. S., Rubinfeld D. (2013), Microeconomics $8^{\text {th }}$ edition, Prentice Hall, New Jersey.

47. Pomboza R., Mbaga M. (2007), The estimation of food demand elasticities in Canada, Agriculture and Agri-Food Canada, Ottawa.

48. Samuelson P. A., Nordhaus W. D. (2010), Economics, McGraw-Hill, New York.

49. Schiller B. R., Gebhardt K. (2016), The Micro Economy Today, $14^{\text {th }}$ edition, McGraw-Hill Education, New York.

50. Shivam N. (2016), Measuring Price Elasticity of Demand: 4 Methods, available at: https://www.economicsdiscussion.net/elasticity-of-demand/measuring-price-elasticity-ofdemand-4-methods/21878.

51. Statistics Lithuania (2003-2015), Economic and Social Development in Lithuania, Statistics Lithuania, Vilnius.

52. Tonsor G. T., Mintert J., Schroeder T. C. (2010), U.S. meat demand: household dynamics and media information impacts, Journal of Agricultural and Resource Economics, 35(1), pp. $1-17$.

53. (2019), Average consumer prices for goods, available at:

http://www.ukrstat.gov.ua/operativ/operativ2018/ct/sctp/Arch_sctp_e.htm.

54. (2019), Average monthly retail prices, available at:

https://osp.stat.gov.lt/statistiniu-rodikliu-analize?hash=60086d42-0846-48b9-8927-

d6abb98552e9\#/.

55. (2019), Calculating Price Elasticities Using the Midpoint Formula, available at: https://courses.lumenlearning.com/economics2e-demo/chapter/calculating-priceelasticities-using-the-midpoint-formula/

56. (2019), Consumer price indices for goods and services, available at: https://ukrstat.org/en/operativ/operativ2010/ct/is_c/arh_isc/arh_iscm10_e.html.

57. (2019), Conversion of 1 EUR to UAH on 01 January 2001, available at: https://fxtop.com/en/historical-exchange-

rates.php?A=1\&C1=EUR\&C2=UAH\&MA=1\&DD1=01\&MM1=01\&YYYY $1=2001 \& B=1$ $\& \mathrm{P}=\& \mathrm{I}=1 \& \mathrm{DD} 2=31 \& \mathrm{MM} 2=10 \& \mathrm{YYYY} 2=2019 \& \mathrm{btnOK}=\mathrm{Go} \% 21$.

58. (2019), Foodstuff consumption per capita, available at:

https://osp.stat.gov.lt/statistiniu-rodikliu-analize?hash=35b84ad8-e279-43f0-a224-

bf0098e3859d\#/. 